\title{
La Reforma a la Educación Básica
}

DOI: https://doi.org/10.32870/dse.v0i9.297

\section{Gildardo Meda Amaral*}

Participar en un debate siempre es una cuestión difícil, sobre todo porque algunos esperan que los argumentos se presenten en blanco y negro, se confronte lo bueno contra lo malo, lo erróneo contra lo positivo. Sin embargo, un verdadero debate sobre la Reforma Educativa tiene que emitir juicios racionales, que rebasen la inmediatez del momento y que valoren los pros y los contras a largo plazo, sin perder de vista los elementos del entorno social que pueden detonar o detener las reformas propuestas.

En ese sentido, el propósito de este escrito es destacar los elementos que considero positivos de la reforma de la educación básica implementada en México, sin dejar de lado que para concretarse positivamente hace falta que se conjuguen una serie de factores. A pesar de que la Reforma Educativa tiene algunos aspectos criticables, o que al menos constituyen todavía una incógnita en su concreción final — a pesar de que estamos en el segundo año del sexenio-, quisiera detenerme a revisar aquellos aspectos positivos de la misma.

La reforma educativa impulsada por el régimen forma parte de una serie de once reformas estructurales con las que se pretende cambiar, de manera radical el rostro al país. Esas reformas son producto del llamado Pacto por México, suscrito por el ejecutivo federal y los tres principales partidos políticos de México.

\section{¿Qué es lo que pretende reformar?}

La educación mexicana, después de la creación de la Secretaría de Educación Pública en 1921, tuvo un crecimiento extraordinario, debido a que se creía que la educación iba a detonar la igualdad social y el desarrollo del país. Sin embargo, a partir de la década de los años setenta del siglo pasado, se empezó a observar que ese crecimiento en la matrícula no tenía su correlato con el propósito de lograr la calidad del servicio educativo.

\footnotetext{
* Profesor-investigador de la Universidad Pedagógica Nacional, Unidad 142 de Tlaquepaque.
} 
Si bien había crecido la matrícula de escolares inscritos en el sistema educativo nacional, al igual que la planta de maestros, muchos de éstos últimos habían sido incorporados al servicio docente una vez que habían terminado la escuela primaria superior (de seis grados) o, inclusive en algunos de los casos la primaria elemental (cuatro grados).

En tiempos modernos y con el afán de subsanar las deficiencias observadas en la calidad de la educación, se firmó el Acuerdo Nacional para la Modernización de la Educación Básica y Normal (ANMEB) el 18 de mayo de 1992, con base en tres ejes: 1) la reorganización del sistema educativo; 2) la reformulación de contenidos y materiales educativos y, 3) la revaloración social de la función magisterial. Como parte de este último apartado, se crea el Programa de Carrera Magisterial, con el propósito de profesionalizar al docente. Sin embargo, a pesar de la suscripción de este acuerdo, los problemas educativos relacionados con la reprobación, la deserción, el ausentismo escolar, mejoraron apenas un poco, pero los relacionados con la calidad educativa siguieron persistiendo.

Ante las limitaciones observadas en el ANMEB, el 20 de junio de 2008 se firma la Alianza por la Calidad de la Educación (ACE), en el que una de sus acciones más significativas fue el establecimiento del Examen Nacional para la Asignación de Plazas Docentes, para incorporar a los nuevos maestros al servicio, con el afán de terminar con el manejo discrecional de plazas docentes, de tal forma que quien quisiera entrar al servicio educativo, tener un incremento de horas o acceder a una doble plaza, lo tendría que hacer por haber ganado esa promoción por medio de un concurso.

Tanto en la firma del ANMEB como de la ACE, jugó un papel protagónico el Sindicato Nacional de Trabajadores de la Educación (SNTE). El cuál no solamente suscribió estos acuerdos, sino que tenía un fuerte peso en la misma Secretaría de Educación Pública y en las Secretarías de Educación de las entidades federativas, de tal manera que muchos de los funcionarios de las mismas eran impuestos, o al menos "palomeados" por el SNTE. Durante el sexenio de Felipe Calderón, por ejemplo, se llegó al extremo de entregar la Subsecretaría de Educación Básica a Fernando González, yerno de la maestra Elba Esther Gordillo.

\section{¿En qué consiste la reforma?}

Con el actual régimen, se observó que los problemas de calidad en el sistema educativo persistían y que haber entregado al SNTE ciertos espacios de poder dentro de la Secretaría había acotado el margen de acción de la autoridad pedagógica. Con las modificaciones implementadas en el ámbito educativo, a diferencia de los últimos cambios que se habían generado en esta materia en el país, el gran ausente fue el SNTE.

Para hacer efectiva la reforma, se impulsaron las modificaciones a los artículos $3^{\circ}$. de la Constitución y 73 y de la Ley General de Educación, también se impulsó la creación del Sistema Nacional del Servicio Profesional Docente y se dotó de autonomía al INEE, que se van a traducir - esperemos-, en la mejora de la calidad de la educación.

Por lo pronto, a partir de las modificaciones constitucionales y de la expedición de las leyes secundarias, desparece o al menos se readecúa el Programa de Carrera Magisterial, la Ley de Escala- 
fón y el Reglamento de Promociones del personal, que si bien sirvieron para promover al personal en servicio con base en méritos, en muchos de los casos cayeron en vicios y desviaciones que los desvirtuaron de su pretensión original. Carrera Magisterial, por ejemplo, fue visto como un programa para incrementar las percepciones salariales de los maestros, pero que poco sirvió para elevar la calidad de la educación (OCE, 2006). Estas nuevas disposiciones tendrán un efecto positivo al "puntismo magisterial", que se basaba en acumular cursos, diplomados, maestrías y doctorados, que poco se reflejaban en la calidad de la enseñanza.

\section{¿Qué pretende la Reforma Educativa?}

Fortalecer la autonomía de gestión de las escuelas. Una de las asignaturas pendientes que se trata de resolver con la reforma, es alentar la participación social en educación, ya que los espacios para que los alumnos, los padres de familia y la sociedad se involucren en los asuntos de la escuela están acotados.

Establecer en forma paulatina las Escuelas de Tiempo Completo. Sobre todo se trata de adecuar la jornada escolar con la jornada laboral de los padres. Es una medida plausible, pero no debemos perder de vista que las escuelas de tiempo completo no aseguran, por sí mismas, la calidad educativa. No tiene caso ofrecer más de lo mismo, si no se transforma la escuela.

Establecer un censo escolar. La realización del censo escolar de 2013 logró tener una rediografía más o menos aproximada del número de escuelas del país, las que son de organización completa e incompleta, el número de alumnos y de maestros. Sin embargo, el Censo debió también contener aspectos relacionados con la calidad de los espacios y materiales educativos.

Crear un Sistema Nacional de Evaluación dando autonomía al INEE. La intención de dotar de autonomía al INEE logró sortear las dudas iniciales con la conformación de su Junta Directiva, porque muchos creíamos que esta institución, al igual que pasa en otros órganos como el IFE, el Tribunal Electoral, la Suprema Corte, entre otros, iban a ser espacios en el que los partidos políticos se repartirían entre ellos los puestos del consejo. Al menos, prevaleció el espíritu de ciudadanizar el INEE.

Crear el Servicio Profesional Docente, que regule las promociones horizontales y verticales. Es un punto destacable, pero no debemos perder de vista que la permanencia en el empleo, no debe

ajustarse a aspectos meramente punitivos, sino que el acompañamiento tiene que estar orientado a la tutoría y a la posibilidad de mejora de la calidad educativa.

\section{A manera de conclusión}

Para responder a la pregunta ¿la reforma educativa logrará elevar la calidad de la educación? Es difícil hacerlo con un rotundo sí, ya que debemos reconocer que es complicado que la Reforma Educativa se refleje en la calidad educativa en el corto plazo. Sin embargo, los pasos más importantes están dados y los resultados de fondo se verán en el mediano y largo plazo. 
Si bien no podemos negar que la implementación de la Reforma Educativa obedece a las presiones de la OCDE, ésta tiene que convertirse en una acción de política educativa que posibilite la necesaria transformación de nuestro sistema educativo; sin dejar de lado que también hace falta una política integral de desarrollo social.

\section{Referencias}

Observatorio Ciudadano de la Educación. Plataforma Educativa Ciudadana 2000-2006.

Presidencia de la República (2013). Decreto por el que se reforman, adicionan y derogan diversas disposiciones de la Ley General de Educación. En DOF, 11 de septiembre de 2013. Recuperado de http://www.presidencia.gob.mx/reformaeducativa/assets/downloads/reforma-a-la-leygeneral-de-educacion.pdf

SEGOB (2013). DECRETO por el que se expide la Ley General del Servicio Profesional Docente. En DOF, 11 de septiembre de 2013. Recuperado de http://www.dof.gob.mx/nota_detalle.php? codigo $=5313843 \&$ fech $a=11 / 09 / 2013$

SEGOB (2013) Constitución Política de los Estados Unidos Mexicanos. Recuperado de http:// www.ordenjuridico.gob.mx/constitucion.php

SEP (1992). Acuerdo Nacional para la Modernización de la Educación Básica y Normal, Recuperado de http://www.sep.gob.mx/work/models/sep1/Resource/b490561c-5c33-4254-ad1caad33765928a/07104.pdf 